\title{
Promotion of Resource Utilization and Livelihood Improvement in the Hindu Kush-Himalaya Region through International Agricultural Cooperation
}

\author{
Ying $\operatorname{Han}^{1}$, Yongqian $\mathrm{Li}^{2}$, * \\ ${ }^{1}$ International Cooperation and Exchange Department, Yunnan Agricultural University, Kunming, Yunnan 650201 \\ ${ }^{2}$ Faculty of Economics and Management, Yunnan Agricultural University, Kunming, Yunnan 650201 \\ *Corresponding author. Yongqian Li \\ E-mail:13987162465@163.com; E-mail: 1169206654@qq.com
}

\begin{abstract}
The Hindu Kush-Himalayan region is an important area where China's "Belt and Road" strategy facing the South Asia. Due to its geographical feature, the complex international political factors have long existed in this region. Consequently, the progress that China promotes its opening-up strategy in South Asia has not advanced as well as it has in other areas. This paper starts with the acute problem of poverty in the region, analyzes the opportunities and challenges in international agricultural cooperation, proposes a cooperative mechanism for mutual benefit and spreads China's advanced experience in antipoverty process. It is suggested to implement international poverty relief project through international agricultural cooperation to promote regional resource utilization and livelihood improvement. We will take economic development as a precursor, build a shared community for people's livelihood, and strengthen mutual political trust among countries in the region. In doing so, we will consolidate the political and economic foundation for the "Belt and Road" strategy exerting its role in South Asia.
\end{abstract}

Keywords-International Agricultural Cooperation; Hindu Kush-Himalaya Region; Livelihood Improvement

\section{INTRODUCTION}

The Hindu Kush-Himalaya Region includes eight countries, namely, Afghanistan, Pakistan, Bhutan, Nepal, Bangladesh, Burma, India and China. Due to its rich and diverse natural and cultural heritage, this region is the home to different ethnic groups in various countries. HKH region runs from the east China to the west Hindu Kush Mountain in Central Asia, totaling over 3500 kilometers that covers Hengduan Mountains, extending Himalaya Mountains and the vast Qinghai Tibet Plateau, boasting the highest ecosystem and rich and diverse natural resources in the world. It is important to spread China's successful experience of poverty relief in the underdeveloped countries in this region by setting up demonstration project of international agricultural cooperation, which intends to improve the production and living conditions of the local people, enhance the selfdevelopment capacity and achieve the goal of reducing poverty in the region. Suppose this experience can be further promoted in the whole HKH region, there will be great improvement for both the exploration and utilization of the mountain resources and livelihood in the poverty-stricken areas. The realization of this project can be taken as an important starting point and support for the implementation of China's "The Belt and Road" initiative in South Asia. When economic development was taken as guidance, there will be prospect of building people's livelihood community political trust between the countries, reinforce political and economic basis for China to facilitate the Belt and Road strategy in South Asia.

\section{WAY FOR CHINA TO EXPAND THE INTERNATIONAL AGRICULTURAL COOPERATION IN THE HINDU KUSH- HIMALAYA REGION}

Generally, the regional distribution of the agricultural international cooperation in China features unbalanced geographical spatial distribution, the one featuring being resource-oriented with more investment in the areas near China, which aligns China's foreign investment theory that stresses the investment destination ranges from the near areas to the far distance. China's agricultural investment in the Hindu Kush-Himalaya region is suggested to start from border trade to enterprise agglomeration, and state-supported or guided model. This form of investment is mainly due to geographical convenience, resource complementarities and ethnic interaction, which can be specified as follows: first, the comparative cost effect of geographical adjacency: the border economy between China and south Asian countries transforms from the marginalization of social and economic development to the cooperation of new economic growth point and close connection; Second, interest-driven effect of complementary resources: social and economic development level of different countries and disparities of the resource endowment formed the resource complementarities, forming the foundation of investment and cooperation. Furthermore, the cascade spread of production technology and comparative advantage of transnational division of multinational labor promoted the investment driving force of resources complementary; Third, the ethnic Chinese is the largest cross-border ethnic group in the region and similarities in culture, customs and languages 
makes easier communication and bilateral cross-border movement generates huge "mediation effect".

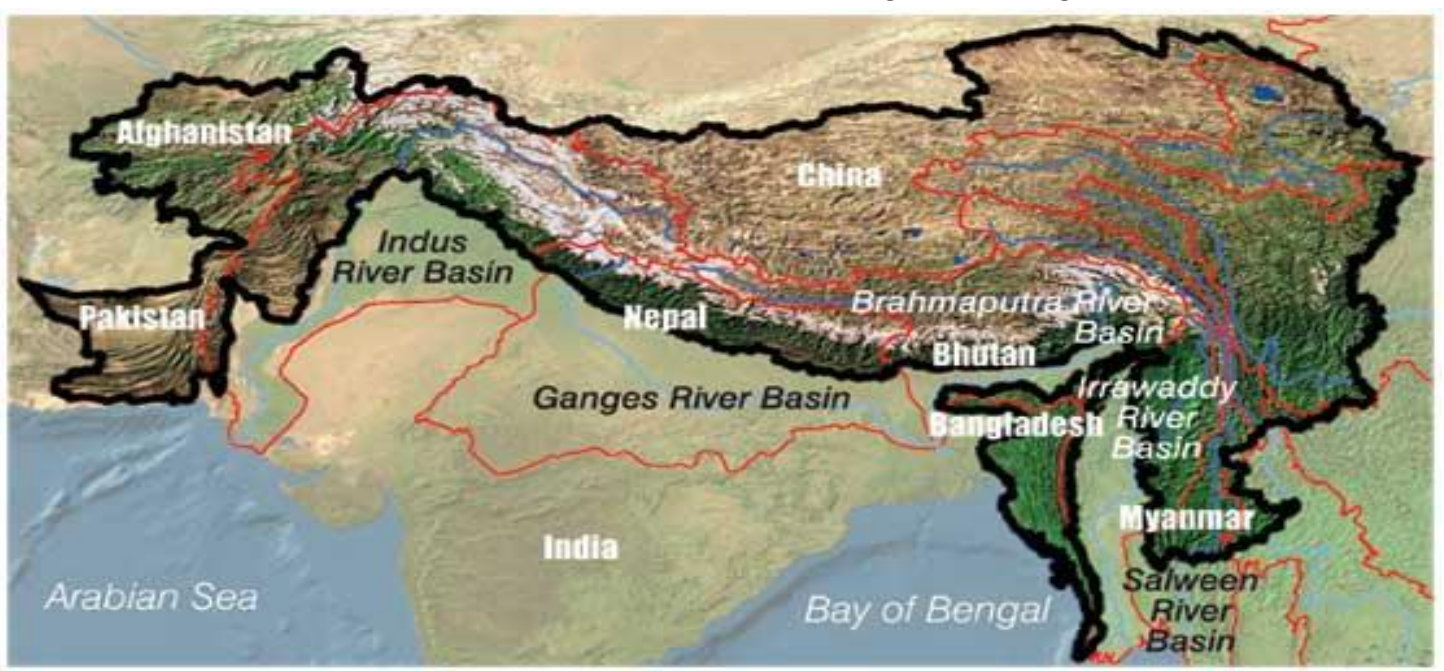

Fig. 1 Hindu Kush-Himalayan Region

\section{CHALLENGES AND OPPORTUNITY}

\section{A. Challenges of international cooperation in agriculture}

First, the mountainous resources are lessened and carrying capacities of the agricultural ecological environment are weakened. The great population pressure in the Hindu KushHimalaya region results in shrunken environmental bearing capacity and extinct or degradation of many wildlife habitats. In subtropical regions, many original grassland ecosystems have been replaced by the traditional agricultural system. It is common to see the grass suffers from the interference of human and livestock activity, and a large number of native vegetation dies out. Secondly, the degree and range of the poverty is huge. Nepal, Afghanistan, Myanmar and Bangladesh are among the least developed countries in the Hindu Kush Himalayas, and it is tricky to find a solution to the problem of food and clothing. According to the report 2016, poverty and common prosperity published by the World Bank, in 2013, 767 million people in the world lived in extreme poverty. Compared with 2012 , the population of the extreme poverty fell by more than one hundred million and the proportion of people living in extreme poverty has fallen from $35 \%$ in 1990 to $11 \%$ in 2013 . Half of the world's poor people live in South Asia, and the gap between the per capita income of the least developed countries and the world's per capita income is widening. In addition, forest resources are reduced and some areas are trapped in a vicious cycle of poverty. Economic development of the countries in the region is unbalanced and economic development is mainly dominated by predatory resource consumption at the expense of sharp reduction of forest coverage rate, causing serious soil and water loss. Meanwhile, reclamation in the mountains further exacerbated the loss of water and soil, resulting in a vicious cycle and further reduction of arable land.

\section{B. Opportunities for international cooperation in agriculture}

First of all, agricultural cooperation is an important part in China's construction of the Bangladesh-China-IndianBurmese economic corridor. In the Hindu Kush-Himalayan region, China, India, Myanmar, and Bangladesh are closed neighbors connected by mountains and rivers and the friendship goes back to ancient times. The four countries have a vast territory of 13.4 million square kilometers and a huge population of nearly 2.8 billion, accounting for $40 \%$ of the world's total population. With abundant products, rich resources, energy and economic complementarities, these countries have huge potential for cooperation. Secondly, South Asia is rich in agricultural resources and agricultural cooperation will be helpful to reduce international poverty. The measures are as the follows: helping the Hindu Kush Himalaya (HKH) mountain countries improve their agricultural production capacity and effectively coping with the food crisis by providing a large number of agricultural machinery, good seeds, fertilizers and other agricultural materials; popularizing the advanced and applicable agricultural production technology to the local people; effectively transform knowledge to technology, and improving the productivity of the local agriculture to reach the goal of international poverty reduction. Moreover, remarkable effects of agricultural investment will have a strong impetus to the regional economy. Presently, there are two ways to invest internationally: land concession and order farming. China's agricultural investment, on the one hand, provides direct employment and income opportunities for farmers in less developed countries in Hindu Kush Himalaya. On the other hand, it also brings other indirect benefits to the less developed countries in the region, such as the development of supporting business, and promotion of agricultural productivity with agricultural technology extension and agricultural infrastructure. 


\section{CONCLUSION}

A. Establish a mutually beneficial and win-win international agricultural cooperation mechanism to create an international community of people's livelihood in the region

Resources acquisition is not the fundamental purpose for China's agricultural investment in the Hindu Kush Himalaya region; instead, we should adhere to the cooperation thought of "building an amicable, tranquil and prosperous neighborhood". We should rely on the favorable conditions of agricultural resources in the surrounding countries and leverage our comparative strengths in capital and agricultural science and technology. The injection of agricultural capital and advanced agricultural production technology will change the traditional agricultural industrial structure and improve the living conditions of the countries of the Hindu Kush Himalaya region. These supports will help to build a closer and a longterm connection, promote economic common benefits and provide material foundation and support for strengthening political trust between China and countries in this region.

\section{B. Construction of the international poverty reduction demonstration projects through agricultural science and technology assistance}

According to the features of photography, we will carry out scientific and technological training on persons in the area of agriculture at the national level, establish national-level overseas training bases at agricultural research institutes in the border provinces. We will carry out systematic training, special training and exchange-type training to improve the professional skills and comprehensive quality of the Chinese and foreign personnel. We will speed up the construction of the international poverty reduction demonstration projects, and support a group of projects on international agricultural cooperation targeted mountainous areas as soon as possible. We will promote the successful model of poverty reduction in the underdeveloped countries or regions in Hindu Kush Himalaya region.

\section{Achieve industrial convergence and expand value-added products}

The concept of green and sustainable development should be integrated into the maintenance of the mountain scenery of Hindu Kush Himalaya by perfecting public facilities and services and implementing the management services of mountain communities. We will expand the multi-function of agriculture by developing farm-based experience, recreation, agricultural tourism or health and step up the integrated development of mountain production, mountain life and mountain ecology with the primary, secondary, and tertiary industries in rural areas, which will explore a set of replicable and stable production and living ways for the improvement of the livelihoods of the rural households in the Kush Himalaya mountain area.

\section{Implementing the resource co-management for mountainous villages revitalization plan}

To ensure that the policy is in line with the public opinion and reduce the interest conflict between the government and the farmers, it is advisable for the farmers to be invited to participate in the establishment of the relevant system for the protection of mountain resources with government institutions in the Hindu Kush Himalaya region. Meanwhile, it is necessary for the government to give the corresponding compensation for the loss of temporary income in the early stage for their involvement in the whole process of protection and sustainable development of mountain resources. As this plan is of great importance when it will bring the benefit for the improvement of local livelihoods, we should promote in the Hindu Kush Himalaya region such comparatively successful projects as national agricultural cooperation and poverty relief project which are facilitated by the "soft power" in an all-round way. The innovative mechanism of "company + cooperatives + farmers" participating breaks down "soft barrier" and lays a solid foundation for enterprise's foreign investment strategy. It is also suggested a regional market center be built in the Hindu Kush region of Himalaya by the integration of urban and rural resources and the development of Internet plus modern agriculture via CSA (community support agriculture). Relying on the consumer market, absorb all kinds of talents to serve in mountainous rural areas so as to achieve the target of drawing closer to the market and keeping poverty away. It is important for the local government to put forward the measures that tackle the challenges between the improvement of the livelihood of the local people and the protection of the resources and environment. With the target poverty reduction initiated and the involvement of community in the management, the government works hard to set up more just and reasonable supporting policies to carry out targeted poverty alleviation by developing industry of distinctively local agricultural products to rejuvenate the rural areas.

\section{ACKNOWLEDGEMENT}

This research was financially supported by International Poverty Reduction Center in China.

\section{REFERENCES}

[1] Krishna P.oli, Lin Wu, Yongmei Zhang, Xiaotong Lv, Zili Fan, Qing Xu. Genetic Resource Acquisition and Benefit Sharing: Opportunities and Challenges in the Hindu Kush Himalayas [J]. Si Chuan Environment, 2014(2):37-42.

[2] The Ministry of Agriculture's Department of International Cooperation, Department of Foreign Economic Cooperation. Report on China's Foreign Agricultural Investment Cooperation in 2012[M]. 2014:12-38.

[3] Shuangshuang Song. Expand Foreign Agricultural Cooperation under the One Belt and One Road Strategy [J]. International Economic Cooperation, 2014(9):63-66.

[4] Zhigang Ma, Qi Wang, Zhihong Tian, Xueling Zhai. to Support the Discussion on the Means of Agricultural Foreign Investment [J]. World Agriculture, 2014(2) 10-13.

[5] Guiming Lu. Rural Complex Pilot Project: Idea Mode and Advance Thought [J]. Sub National Fiscal Research, 2017(7):8-13 